\title{
PENGARUH FINANCING DEPOSITE RATIO (FDR), CAPITAL ADEQUACY RATIO (CAR), DAN BIAYA OPERASIONAL PENDAPATAN OPERASIONAL (BOPO) TERHADAP RETURN ON ASSET (ROA) PADA BANK SYARIAH MANDIRI TAHUN 2013-2017
}

\author{
Luluk Anggraeni dan Mushawir \\ Universitas Mercu BuanaYogyakarta \\ Email : anggralulux@gmail.com, momojogja50@gmail.com
}

\begin{abstract}
ABSTRAK
The purpose of this research is to examine the influence of Capital Adequacy Ratio $(C A R)$, Financing Deposit Ratio (FDR), and Operational Cost of Operating Income (ROOP) to Bank Syariah Mandiri The sample in this research is obtained by purposive sampling The criteria of the banks collected in this study are the Financial Statements of the End of the Month of the Month (March, June, September, and December) for the years 2013-2016 and the Final Financial Statements of the Quarterly Months (March, June, and September) for 2017 at Bank Syariah Independent. Result of t test show that CAR variable obtained by regression coefficient equal to -0,753 with significance value equal to 0,463 so that CAR have no effect to ROA. FDR obtained regression coefficient of 1,500 with a significance value of 0.154 so that FDR does not affect the ROA. BOPO obtained regression coefficient of -10.663 with a significance value of 0.000 so that significant effect on ROA. F test results show that CAR, FDR, and BOPO variables simultaneously affect the ROA is indicated with a significance value of less than 0.05 is 0.000. The result of $R^{2}$ test shows that the predictive ability of four independent variables (CAR, FDR, BOPO, ROA) is $96.30 \%$, while the rest of $3.70 \%$ is influenced by factors not examined in this research.
\end{abstract}

Keywords: Financing Deposite Ratio (FDR), Capital Adequacy Ratio (CAR), Biaya Operasional Pendapatan Operasional (BOPO) dan Return On Asset (ROA)

\section{A. PENDAHULUAN}

Intermediary Institution (perantara keuangan) yakni suatu lembaga yang mampu menyalurkan dana yang dimiliki oleh unit ekonomi yang surplus (kelebihan dana) kepada unit-unit ekonomi yang membutuhkan bantuan dana. Kemampuan bank dalam memberikan pinjaman kepada masyarakat tentunya harus diimbangi dengan banyaknya simpanan yang diperoleh bank. Bank tidak dapat berjalan tanpa adanya penerimaan dari masyarakat dalam bentuk simpanan. Namun, bank juga tidak dapat memaksimalkan labanya hanya dengan menerima simpanan dari masyarakat (Widowati, 2015).

Tujuan bank secara mikro adalah menciptakan laba, sedangkan tujuan makronya menurut pasal 3 UU No. 10/1998 adalah menunjang pelaksanaan pembangunan nasional. Agar dapat tercapai tujuan tersebut maka bank harus benar-benar menjalankan fungsinya dengan baik, diantaranya adalah fungsi penghubung (financial intermediary) antara savers (pihak kelebihan dana) 
dengan lenders (pihak yang kekurangan dana), fungsi pembangunan, fungsi pelayanan, dan fungsi transmisi. Untuk dapat menjalankan fungsi tersebut maka bank harus memiliki manajemen dana yang baik. Manajemen dana adalah suatu proses pengelolaan penghimpunan danadana masyarakat ke dalam bank dan pengelolaan dana-dana tersebut bagi kepentingan bank dan masyarakat pada umumnya, serta pemupukannya secara optimal melalui penggerakan semua sumber daya yang tersedia demi mencapai tingkat rentabilitas yang memadai, sesuai dengan batas ketentuan yang berlaku (Purba, 2011).

Upaya untuk memenuhi tingkat kecukupan modal sebagaimana yang telah diatur oleh Bank Indonesia merupakan hal yang amat penting untuk diperhatikan karena tingkat kecukupan modal mencerminkan kemampuan bank dalam menanggung resiko kerugian yang mungkin timbul. Selain itu, tingkat modal yang tinggi akan meningkatkan cadangan kas yang dapat digunakan untuk memperluas pembiayaan, memperluas jaringan kantor serta menyediakan fasilitas kantor yang modern dan sistem telekomunikasi yang canggih, sehingga dapat membuka peluang lebih besar dalam meningkatkan profitabilitas bank.

Untuk mencapai tingkat profitabilitas yang diharapkan perlu dilakukan berbagai usaha dan strategi guna mendukung tercapainya tingkat kesehatan perbankan yang optimal. Usaha tersebut salah satunya dapat dilakukan dengan memantapkan kembali struktur modal perbankan yang menyelaraskan skala usaha dengan kebutuhan permodalan guna mempertinggi kemampuan menyerap risiko usaha, dan dengan melakukan peningkatan efisiensi operasional agar mampu mendorong profitabilitas ke tingkat yang lebih tinggi (Purba, 2011).

\section{B. TINJAUAN PUSTAKA}

\section{Financing Deposite Ratio (FDR)}

FDR merupakan Rasio Likuiditas, yaitu analisis yang dilakukan terhadap kemampuan bank dalam memenuhi kewajiban jangka pendeknya atau kewajiban yang sudah jatuh tempo. Likuiditas adalah kemampuan bank untuk membayar semua utang jangka pendeknya dengan alat-alat likuid yang dikuasainya (Hasibuan,2001). Untuk mengukur Rasio FDR menggunakan formula sebagai berikut :

$F D R=\frac{\text { Jumlah Kredit yang Diberikan }}{\text { Jumlah Dana Pihak Ketiga }} \times 100 \%$
Yang dimaksud dengan Dana Pihak Ketiga (DPK) adalah dana yang berasal dari nasabah seperti simpanan dalam bentuk tabungan, giro dan deposito.

\section{Capital Adequacy Ratio (CAR)}

Kecukupan modal dapat dihitung dengan menggunakan rasio Capital Adequacy Ratio (CAR).Capital Adequacy Ratio (CAR) ini merupakan jenis rasio solvabilitas, yaitu rasio yang digunakan untuk mengukur efisiensi bank dalam menjalankan aktivitasnya, selain itu juga merupakan ukuran kemampuan bank mencari sumber dana untuk membiayai kegiatannya. Menurut Makoagow (2015) pada bank syariah, perhitungan ATMR sedikit berbeda dari bank konvensional. Aktiva pada bank syariah dibagi atas aktiva yang dibiayai dengan modal sendiri serta aktiva yang didanai oleh rekening bagi hasil. Rumus untuk mengitung besarnya CAR adalah sebagai berikut :

$\mathrm{CAR}=\frac{\text { Modal Bank }}{\text { Aktiva Tertimbang Menurut Risiko (ATMR) }} \times 100 \%$ 


\section{Biaya Operasional Pendapatan Ope- rasional (BOPO)}

Rasio Biaya Operasional Pendapatan Operasional (BOPO) yaitu, rasio perbandingan antara Biaya Operasional dengan Pendapatan Operasional, semakin rendah tingkat Rasio Biaya Operasional Pendapatan Operasional (BOPO) berarti semakin baik kinerja manajemen bank tersebut, karena lebih efisien dalam menggunakan sumber daya yang ada di perusahaan (Riyadi, 2006). Biaya operasional merupakan biaya yang dikeluarkan oleh bank dalam rangka menjalankan aktivitas usaha utamanya seperti biaya bunga, biaya pemasaran, biaya tenaga kerja, dan biaya operasional lainnya. Secara umum untuk menghitung BOPO dapat digunakan rumus sebagai berikut :

$$
\text { BOPO }=\frac{\text { Beban Operasional }}{\text { Pendapatan Operasional }} \times 100 \%
$$

\section{Return On Asset (ROA)}

Return On Asset adalah rasio yang digunakan untuk mengukur kemampuan manajemen bank dalam memperoleh keuntungan (laba) secara keseluruhan. Return On Asset (ROA) ini termasuk dalam rasio rentabilitas, yang bertujuan untuk mengukur efektivitas bank dalam mencapai tujuannya. Semakin besar ROA suatu bank, semakin besar pula tingkat keuntungan yang dicapai bank tersebut dan semakin baik pula posisi bank tersebut dalam penggunaan asset. Biasanya apabila profitabilitas tinggi akan mencerminkan laba yang tinggi dan ini akan mempengaruhi harga saham bank tersebut. Semakin besar Return On Asset (ROA) suatu bank, semakin besar pula tingkat keuntungan yang dicapai bank tersebut dan semakin baik pula posisi bank dari segi penggunaan asset (Dendawijaya, 2003).

Untuk menghitung ROA dapat dilakukan dengan menggunakan rumus sebagai berikut :

$$
\text { ROA }=\frac{\text { Laba sebelum pajak }}{\text { Total Aktiva }} \times 100 \%
$$

Laba sebelum pajak adalah laba rugi bank yang diperoleh dalam periode berjalan sebelum dikurangi pajak. Sedangkan total aktiva merupakan komponen yang terdiri atas kas, giro pada BI, pembiayaan dengan prinsip bagi hasil, pembiayaan dengan prinsip jual beli, pembiayaan dengan prinsip sewa, aktiva tetap, dan lain-lain

Berikut ini ditampilkan skema kerangka penelitian

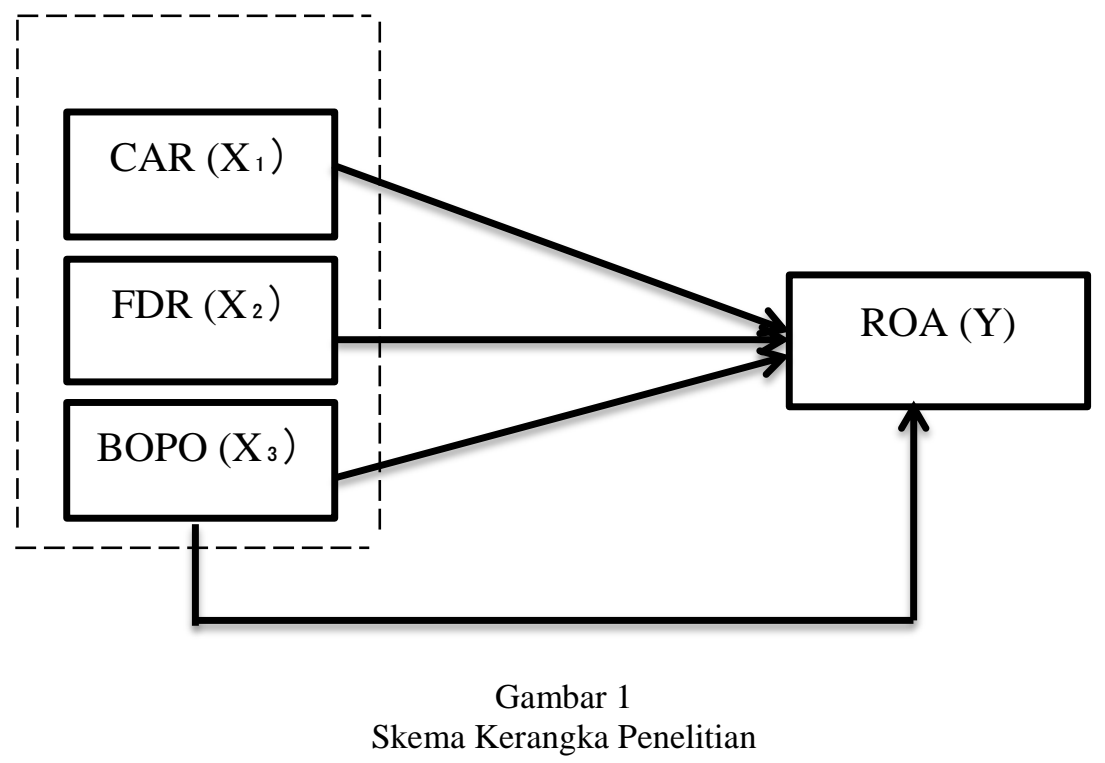




\section{METODE PENELITIAN}

Populasi dalam penelitian ini adalah Laporan Keuangan Akhir Triwulan bulan (Maret, Juni, September, dan Desember) untuk tahun 2013-2016 dan Laporan Keuangan Akhir Triwulan Bulan (Maret, Juni, dan September) untuk tahun 2017 pada Bank Syariah Mandiri. Dengan demikian total populasi dalam penelitian ini sebanyak 19 bulan/peristiwa. Pengambilan sampel yang digunakan dalam penelitian ini menggunakan teknik purposive sampling.

Jenis data yang digunakan dalam penelitian ini adalah data kuantitatif, yaitu data yang diperoleh dalam bentuk angka-angka dari laporan keuangan bank yang terdiri atas Laporan Keuangan
Akhir Triwulan bulan (Maret, Juni, September, dan Desember) untuk tahun 2013-2016 dan Laporan Keuangan Akhir Triwulan bulan (Maret, Juni, dan September) untuk tahun 2017 pada Bank Syariah Mandiri. Sumber data diperoleh dari web site resmi Bank Syariah Mandiri (http://www.syariahmandiri.co.id).

Dalam penelitian ini variabel dependennya adalah Return On Asset (ROA). Sedangkan variabel independennya Capital Adequacy Ratio (CAR), Financing Deposit Ratio (FDR), dan Biaya Operasional Pendapatan Operasional (BOPO). Sedangkan alat analisis yang digunakan dalam penelitian ini adalah regresi linear berganda.

\section{HASIL PENELITIAN}

Setelah diolah dengan menggunakan SPSS, diperoleh hasil sebagai berikut :

Tabel 1

Hasil Uji Analisis Regresi Linear Berganda

Coefficients $^{\mathrm{a}}$

\begin{tabular}{|c|c|c|c|c|c|c|}
\hline \multirow{2}{*}{\multicolumn{2}{|c|}{ Model }} & \multicolumn{2}{|c|}{$\begin{array}{l}\text { Unstandardized } \\
\text { Coefficients }\end{array}$} & \multirow{2}{*}{$\begin{array}{c}\text { Standardized } \\
\text { Coefficients } \\
\text { Beta }\end{array}$} & \multirow[t]{2}{*}{$\mathrm{t}$} & \multirow[t]{2}{*}{ Sig. } \\
\hline & & B & Std. Error & & & \\
\hline \multirow{4}{*}{ 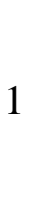 } & (Constant) & 7.202 & 1.536 & & 4.689 & .000 \\
\hline & CAR & -.023 & .030 & -.039 & -.753 & .463 \\
\hline & FDR & .013 & .009 & .118 & 1.500 & .154 \\
\hline & BOPO & -.078 & .007 & -.903 & -10.663 & .000 \\
\hline
\end{tabular}

a. Dependent Variable: ROA

Sumber : Data dioleh SPSS

Berdasarkan Tabel 1, maka dapat diuraikan hasilnya sebagai berikut :

a. Dari persamaan regresi linear berganda diatas, diketahui mempunyai konstanta sebesar 7,202 dengan tanda positif. Sehingga besaran konstanta menunjukkan bahwa jika variabel-variabel independen (FDR, CAR, dan BOPO) diasumsikan konstan, maka variabel dependen yaitu ROA akan naik sebesar 7,202\%.

b. Koefisien regresi $X_{1}(C A R)$ dari perhitungan linier berganda didapat nilai coefficients $\left(b_{1}\right)=-0,023$. Hal ini berarti setiap ada peningkatan $1 \%$ CAR $\left(\mathrm{X}_{1}\right)$ maka ROA (Y) akan menurun sebesar $-0,023 \%$ dengan anggapan variabel FDR $\left(\mathrm{X}_{2}\right)$, dan 
variabel $\mathrm{BOPO} \quad\left(\mathrm{X}_{3}\right)$ adalah konstan.

c. Koefisien regresi $\mathrm{X}_{2}$ (FDR) dari perhitungan linier berganda didapat nilai coefficients $\left(b_{2}\right)=0,013$. Hal ini berarti setiap ada peningkatan $1 \%$ FDR $\left(\mathrm{X}_{2}\right)$ maka ROA (Y) akan meningkatkan sebesar $0,013 \%$ dengan anggapan variabel CAR
$\left(\mathrm{X}_{1}\right)$, dan variabel $\mathrm{BOPO}\left(\mathrm{X}_{3}\right)$ adalah konstan.

d. Koefisien regresi $\mathrm{X}_{3}(\mathrm{BOPO})$ dari perhitungan linier berganda didapat nilai koefisien $\left(b_{3}\right)=-0,078$. Hal ini berarti setiap ada peningkatan $1 \%$ BOPO $\left(\mathrm{X}_{3}\right)$ maka ROA (Y) akan menurun sebesar $0,078 \%$ dengan anggapan variabel CAR $\left(\mathrm{X}_{1}\right)$, dan variabel FDR $\left(\mathrm{X}_{2}\right)$ adalah konstan.

Tabel 2

Hasil Uji hipotesis secara parsial (Uji t)

Coefficients $^{\mathrm{a}}$

\begin{tabular}{|c|c|c|c|c|c|c|}
\hline \multirow{2}{*}{\multicolumn{2}{|c|}{ Model }} & \multicolumn{2}{|c|}{$\begin{array}{c}\text { Unstandardized } \\
\text { Coefficients }\end{array}$} & \multirow{2}{*}{$\begin{array}{c}\begin{array}{c}\text { Standardized } \\
\text { Coefficients }\end{array} \\
\text { Beta }\end{array}$} & \multirow[t]{2}{*}{$\mathrm{t}$} & \multirow[t]{2}{*}{ Sig. } \\
\hline & & B & Std. Error & & & \\
\hline \multirow{4}{*}{1} & (Constant) & 7.202 & 1.536 & & 4.689 & .000 \\
\hline & CAR & -.023 & .030 & -.039 & -.753 & .463 \\
\hline & FDR & .013 & .009 & .118 & 1.500 & .154 \\
\hline & BOPO & -.078 & .007 & -.903 & -10.663 & .000 \\
\hline
\end{tabular}

a. Dependent Variable: ROA

Sumber : Data diolah SPSS

Hasil regresi berganda dapat menganalisis pengaruh dari masingmasing variabel CAR, FDR, dan BOPO terhadap ROA dapat dilihat dari arah tanda dan tingkat signifikan (probabilitas). Hanya variabel FDR mempunyai arah yang positif, sedangkan variabel CAR dan BOPO menunjukkan arah negatif. Dari ketiga variabel tersebut hanya variabel BOPO yang berpengaruh signifikan terhadap ROA karena nilai signifikan lebih kecil dari 0.05, sedangkan variabel CAR dan FDR tidak berpengaruh secara signifikan terhadap ROA karena nilai signifikannya lebih besar dari 0.05 .

Dari hasil perhitungan dengan menggunakan progam SPSS dapat diketahui bahwa hasil uji t untuk variabel CAR $\left(\mathrm{X}_{1}\right)$ diperoleh hasil $t_{\text {hitung }}$ sebesar 0,753 dengan probabilitas sebesar 0,463. Nilai probabilitas tersebut lebih besar dari $0,05(0,463>0,05)$ dengan demikian $\mathrm{Ho}_{1}$ diterima dan $\mathrm{Ha}_{1}$ ditolak. Jadi dapat dikatakan bahwa tidak ada pengaruh yang signifikan antara CAR terhadap ROA. Hasil uji t untuk variabel FDR $\left(\mathrm{X}_{2}\right)$ diperoleh hasil $\mathrm{t}_{\text {hitung }}$ sebesar 1,500 dengan probabilitas sebesar 0,154. Nilai probabilitas lebih besar dari 0,05 $(0,154>0,05)$ maka dengan demikian $\mathrm{Ho}_{2}$ diterima dan $\mathrm{Ha}_{2}$ ditolak. Jadi dapat dikatakan bahwa tidak ada pengaruh yang signifikan antara FDR terhadap ROA.

Sedangkan hasil uji $\mathrm{t}$ untuk variabel BOPO $\left(\mathrm{X}_{3}\right)$ diperoleh hasil $\mathrm{t}_{\text {hitung }}$ sebesar $-10,663$ dengan probabilitas sebesar 0,000 . Nilai probabilitas tersebut lebih kecil dari $0,05 \quad(0,000<$ $0,05)$ dengan demikian $\mathrm{Ho}_{3}$ ditolak dan $\mathrm{Ha}_{3}$ diterima. Jadi dapat dikatakan bahwa ada pengaruh yang signifikan antara BOPO terhadap ROA. 
Tabel 3

Hasil Uji hipotesis secara simultan (Uji F)

ANOVA $^{\mathrm{a}}$

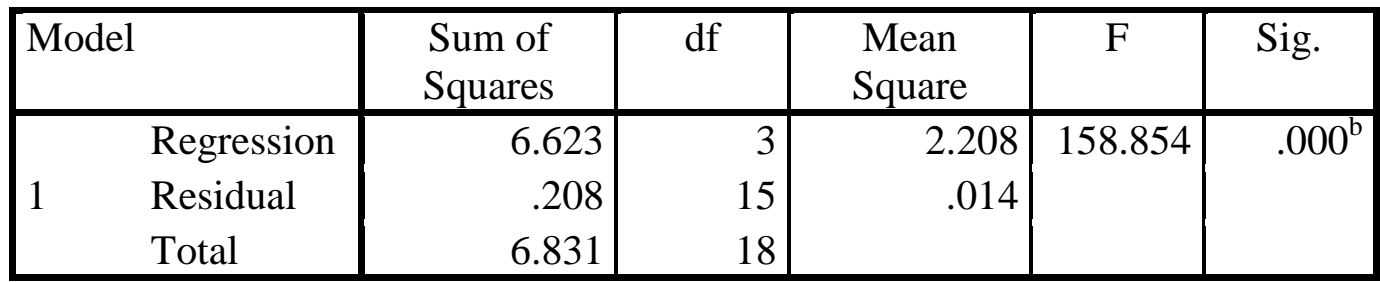

a. Dependent Variable: ROA

b. Predictors: (Constant), BOPO, CAR, FDR

Sumber : Data diolah SPSS

Hasil perhitungan dengan menggunakan progam SPSS dapat diketahui bahwa $\mathrm{F}$ hitung sebesar 158,854 dengan nilai probabilitas sebesar 0,000 , karena nilai probabilitas lebih kecil dari 0,05 maka Ho ditolak dan Ha diterima. Jadi dapat dikatakan bahwa variabel independen berpengaruh secara simultan terhadap variabel dependen sehingga hipotesis yang diajukan yaitu CAR, FDR, dan BOPO berpengaruh secara simultan terhadap ROA pada Bank Syariah Mandiri. Artinya setiap perubahan yang terjadi pada variabel independen yaitu CAR, FDR, dan BOPO secara simultan atau bersama-sama akan berpengaruh pada ROA bank syariah mandiri.

\section{E. PEMBAHASAN}

Dari hasil penelitian diperoleh koefisien transformasi regresi sebesar $-0,023$ dengan nilai signifikansi sebesar 0,463 dan nilai ini lebih besar dari 0,05 maka dapat disimpulkan bahwa CAR tidak berpengaruh terhadap ROA pada Bank Syariah Mandiri.

Diperoleh juga koefisien regresi sebesar 0,013 dan nilai signifikansi sebesar 0,154 , artinya lebih besar dari 0,05 . Karena tingkat signifikansinya melebihi dari $0,05 \%$ maka dalam hal ini pengaruh FDR terhadap ROA tidak signifikan. Sehingga dapat disimpulkan bahwa FDR tidak berpengaruh terhadap ROA pada Bank Syariah Mandiri.

Berdasarkan persamaan regresi terlihat bahwa koefisien untuk BOPO bernilai negatif $-0,078$, sehingga dapat diartikan bahwa pengaruh yang diberikan oleh variabel BOPO terhadap ROA adalah negatif. Nilai BOPO berbanding terbalik dengan nilai ROA, berarti jika nilai BOPO meningkat maka nilai ROA menurun, begitupun sebaliknya. Koefisien regresi sebesar $-0,078$ berarti setiap peningkatan BOPO sebesar $1 \%$ akan menurunkan ROA sebesar $0,078 \%$. Namun, dari Tabel 2 yang menunjukkan hasil pengujian parsial (uji t) antara BOPO terhadap profitabilitas (ROA) menunjukkan nilai signifikansi sebesar 0,000 yang artinya nilai signifikansinya dibawah 0,05. Hal ini berarti bahwa variabel BOPO sangat pengaruh terhadap ROA secara parsial.

Setelah dilakukan uji $\mathrm{F}$ terlihat bahwa secara bersama-sama terdapat pengaruh yang signifikan antara CAR, FDR, dan BOPO terhadap ROA Bank Syariah Mandiri. Hal ini dibuktikan oleh hasil perhitungan nilai $\mathrm{F}$ sebesar 158,854 dan nilai signifikasi $\mathrm{F}$ sebesar 0,000 atau lebih kecil dari 5\%. Sedangkan kontribusi yang diberikan variabel likuiditas, struktur modal, dan efisiensi operasional terhadap profitabilitas sebesar 96,30\%. Sisanya $3,70 \%$ dipengaruhi oleh variabel lain yang tidak diteliti dalam penelitian ini, misal ukuran perusahaan, pertum- 
buhan ekonomi, tingkat inflasi, tingkat suku bunga dan lain-lain. Hal ini menunjukkan bahwa CAR, FDR, dan BOPO memiliki peranan yang sangat penting dalam mempengaruhi perolehan laba atau profitabilitas yang diukur dengan ROA.

\section{F. KESIMPULAN}

Berdasarkan hasil penelitian terhadap permasalahan yang ada, maka dapat diambil kesimpulan sebagai berikut:

1. Financing Deposite Ratio (FDR) tidak berpengaruh terhadap ROA pada Bank Syariah Mandiri.

2. Capital Adequacy Ratio (CAR) tidak berpengaruh terhadap ROA pada Bank Syariah Mandiri.

3. Biaya Operasional Pendapatan Operasional (BOPO) berpengaruh terhadap ROA pada Bank Syariah Mandiri.

4. Financing Deposite Ratio (FDR), Capital Adequacy Ratio (CAR), dan Biaya Operasional Pendapatan Operasional (BOPO) secara bersamasama berpengaruh signifikan terhadap Return On Asset (ROA). Artinya, setiap perubahan yang terjadi pada variabel independen yaitu CAR, FDR, dan BOPO secara simultan atau bersama-sama akan berpengaruh pada Return On Assets (ROA) pada Bank Syariah Mandiri.

\section{Saran}

Berdasarkan hasil analisis pembahasan serta beberapa kesimpulan pada penelitian ini, adapun saran-saran yang dapat diberikan melalui hasil penelitian ini agar mendapatkan hasil yang lebih baik, yaitu:

1. Bagi peneliti selanjutnya diharapkan dapat meneliti dengan variabelvariabel lain diluar variabel ini agar memperoleh hasil yang lebih bervariatif yang dapat menggambarkan hal-hal apa saja yang dapat berpengaruh terhadap ROA dan dapat memperpanjang periode pengamatan dan disarankan untuk memperluas cakupan penelitian tentang pengaruh rasio keuangan terhadap kemampuan manajemen bank dalam memperoleh keuntungan secara keseluruhan dengan menggunakan rasio-rasio lain selain rasio yang dipakai pada penelitian ini.

2. Berusaha menjaga nilai FDR pada level yang optimal dengan memperhatikan batas yang ditentukan. Sehingga akan menaikkan profitabilitas dengan cara penanganan kredit yang bermasalah secara antisipatif, proaktif dan disiplin. Dengan demikian dapat secara dini mendeteksi potensi timbulnya kredit bermasalah, misalnya berupa penyelamatan kredit jika kondisi usaha masih baik. Selain itu kenaikan rasio FDR melalui peningkatan jumlah kredit yang dicairkan dengan tetap menggunakan prinsip kehati-hatian dapat dilakukan oleh manajemen dalam rangka meningkatkan laba bank.

3. BOPO berpengaruh negatif terhadap profitabilitas bank, sehingga pengambil kebijakan perlu melihat tingkat efisiennya menjaga agar jumlah persentase BOPO tidak membengkak, atau tidak lebih dari $92 \%$ sesuai dengan ketentuan Bank Indonesia. Oleh karena itu agar menekan biaya operasional dan meningkatkan pendapatan operasional. Pengeluaran biaya yang kecil dapat dilakukan dengan cara efisiensi kerja. Diantaranya dengan meminimalkan risikorisiko kredit, memperbaiki manajemen investasinya, efisiensi kerja karyawan dan pengurangan aktiva tetap. Bank harus menetapkan atau mempunyai prinsip kehati-hatian untuk diterapkan efisiensi perbankan. 
4. Bagi Bank Syariah Mandiri hendaknya meningkatkan nilai CAR. Misal dengan menambah setoran modal pemilik, melakukan penjualan aset yang tidak produktif yang akan mengurangi ATMR dan berdampak positif terhadap CAR. Dengan caracara tersebut CAR akan meningkat, sehingga profitabilitas yang diproksikan dengan ROA bank juga akan meningkat.

\section{DAFTAR PUSTAKA}

Afriyeni. 2013. Analisis Pengaruh Rentabilitas Terhadap Harga Saham Perbankan Di Bursa Efek Indonesia. Jurnal KBP Vol 1 - No. 3 Desember 2013.

Bernardin, Deden Edwar Yoke. 2016. Pengaruh CAR Dan LDR Terhadap Return On Assets. Jurnal Ecodemica, Vol. IV, No. 2, September 2016.

Dendawijaya, Lukman. 2003. Lima Tahun Penyehatan Perbankan Nasional 1998-2003. Bogor Selatan: Ghalia Indonesia.

Dendawijaya, Lukman. 2005. Manajemen Perbankan. Penerbit Ghalia Indonesia, Jakarta.

Fiscal, Yunus, Lili Lusiana. 2014. Pengaruh Capital Adequacy Ratio (CAR), Loan To Deposite Ratio (LDR), Biaya Operasional Dan Pendapatan Operasional (BOPO) Terhadap Profitabilitas BPR (Studi Kasus pada BPR di Provinsi Lampung Tahun 2010 - 2012). JURNAL Akuntansi \& Keuangan Vol. 5, No. 2, September 2014.

Ghozali, Imam. 2005. Aplikasi Analisis Multivariate dengan Program SPSS. Semarang: FE UNDIP.

Ghozali, Imam. 2006. Multivariate Lanjutan dengan Program SPSS. Semarang: Badan Penerbit Universitas Diponegoro.

Hasibuan, Malayu S.P. 2001. Dasar-dasar Perbankan. Jakarta: Bumi Aksara.

Https://www.syariahmandiri.co.id/tentang-kami/company-report/laporan-keuangan/ laporan-bulanan. Laporan Keuangan Bulanan. Diakses Tanggal: 21 November 2017.

Iskandar.2008. Metodologi Penelitian Pendidikan dan Sosial (Kuantitatif dan Kualitatif). Jakarta: Gaung Persada Press.

Kasmir. 2008. Manajemen Perbankan Edisi Revisi, Jakarta: PT. Raja Grafindo Persada.

Ma'isyah, Rifqul, Imron Mawardi. 2015. Pengaruh Kecukupan Modal, Fungsi Intermediasi, Efisiensi Operasional, Dan Pembiayaan Bermasalah Terhadap Profitabilitas (Studi pada Bank Syariah Periode Januari 2010 - Juli 2014). Jurnal JESTT Vol. 2 No. 3 Maret 2015.

Mokoagow, Sri Windarti. 2015. Faktor-Faktor yang Mempengaruhi Profitabilitas Bank Umum Syariah di Indonesia. Jurnal EB BANK Vol.6- No.1 Juli 2015.

Muhammad, Pengantar Akuntansi Syariah Edisi 2. Jakarta: Salemba Empat, 2005 
Munawir, S., 2002, Manajemen Perbankan. Yogyakarta

Munawir. 2007. Analisis Laporan Keuangan Edisi Ketiga belas. Yogyakarta: Liberty

Purba, Daris. 2011. Pengaruh Kecukupan Modal, Likuiditas, dan Efisiensi Operasional Terhadap Profitabilitas Pada PT. Bank Muamalat Indonesia, Tbk. Skripsi Program Studi Muamalat Fakultas Syariah Dan Hukum UIN Syarif Hidayatullah Jakarta. Terpublikasi Melalui Link:www.repository.uinjkt.ac.id. Diakses tanggal: 22 September 2017.

Rivai, Veithzal, Sofyan Basir, dkk. 2013. Cetakan Ke-1. Januari 2013. Commercial Bank Management Manajemen Perbankan Dari Teori Ke Praktik. PT. Raja Grafindo Persada Jakarta.

Riyadi, S. 2006. Banking Assets And Liability Management. Jakarta: Lembaga Penerbit Fakultas Ekonomi Universitas Indonesia.

Riyanto, Bambang. 2001. Dasar-dasar Pembelanjaan Perusahaan. Yogyakarta: Andi Offset.

Santoso, Rudy Tri. 2000. Prinsip Dasar Akuntansi Perbankan. Yogyakarta: Andi Offset.

Siamat, Dahlan. 1993. Manajemen Bank Umum. Jakarta: Intermedia.

Sudarsono, Heri. 2004. Bank Dan Lembaga Keuangan Syariah. Yogyakarta: Ekonisia, 2004.

Sudjana. 2005. Metode Statisika. Bandung: Tarsito, 2005.

Thalib, Djamil. 2016. Intermediasi, Struktur Modal, Efisiensi, Permodalan Dan Risiko Terhadap Profitabilitas Bank. Jurnal Keuangan dan Perbankan, Vol. 20, No. 1 Januari 2016

Widowati, Sari Ayu. 2015. Pengaruh Rasio Keuangan Terhadap Profitabilitas Perbankan Di Indonesia. Jurnal Ilmu \& Riset Akuntansi Vol. 4 No. 62015. 